\title{
Millennium Development Goals (MDGs) and the UN Post-2015 Global Development Agenda: Implications for Africa
}

\author{
G. S. Mmaduabuchi Okeke ${ }^{1 *}$ and Uche Nwali ${ }^{2}$ \\ ${ }^{1}$ Department of Political Science, University of Lagos, Akoka, Yaba, Lagos, Nigeria \\ ${ }^{2}$ University of Lagos, Lagos, Nigeria
}

\begin{abstract}
The United Nations declared the Millennium Development Goals (MDGs) in the year 2000 with the aim of reducing to the barest minimum, by 2015, global poverty and hunger; illiteracy; gender inequality; child and maternal mortality; HIV/AIDS and other world development challenges. Unfortunately, available evidence shows that most, if not all countries in Africa will not achieve the MDGs by 2015, hence the setting up of the UN System Task Team to design a post-2015 Global Development agenda. This response serves as a clarion call for African political leaders who, for too long, have failed to take Africa's development seriously. The paper examines these deficiencies and also explains why the MGDs are failing in Africa. It adapts qualitative methodology and deploys data from secondary sources. We state that while devising a post-MDG Agenda is a lofty idea, the failure of African leadership to be at the forefront in shaping and determining its contents will create the opportunity for the emergence of a global development paradigm that only satisfies the politico-economic whims and caprices of the donor nations and their institutions for global hegemony. Using a symbiotic development paradigm as the analytical tool, we contend that for UN post-2015 Global Development Agenda to be successful and achievable, it must be comprehensive, inclusive and symbiotic for all nations. We recommend that African leadership should try and become an active participant in the post-2015 global development debate.
\end{abstract}

Key Words: Africa, millennium development goals, United Nations, post-2015, development agenda, implications

\section{Introduction}

Barely two years remaining, there are genuine indications that the Millennium Development Goals (MDGs) may not be achieved in the world's poorest countries particularly those in Africa. Although the MDGs agenda has made some impact in reducing child and maternal mortality, the scourge of HIV/ AIDS and malaria as well as illiteracy in Africa, extant socio-economic realities and statistics indicate that most countries in the continent are still suffering from extreme poverty and hunger as well as preventable diseases. The general consensus in Africa is that MDGs agenda has not solved the global development crisis for which it was designed, at least in Africa. While some attribute this failure to inadequate funding, others blame it on western led-development strategy.

However, there is no doubt that Africa's development conundrums would have been worse if not for the MDGs. That is why it is very necessary to consider the likely implications of the post-2015 Global Development Agenda on Africa vis-a-vis the passive

\footnotetext{
${ }^{*}$ Corresponding author
}

role being played by the African political leadership in shaping the likely outcome. It also looks at how the emerging global issues and development challenges like high graduate unemployment, terrorism and global warming can be factored into the post-MDG paradigm.

Since it is believed that Africa's development will face more difficulties if the MDGs cease to be, this paper attempts to appraise the UN Task Team on the Post-2015 Development Agenda so as to bring to the fore how best it could be designed, in order to incorporate the emerging development challenges and to make the entire global development agenda achievable especially in Africa where development is most needed.

\section{Methodology}

This study deploys qualitative methodology. Data for the analysis are gleaned from secondary sources which include; textbooks, journals, newspapers, conference papers, BBC news and the internet. These data are assessed from the University of Lagos Library and Bookshop as well as the personal library of the writer. The data collected, are collated and analyzed descriptively.

Print ISSN 2329-0781 - Online ISSN 2329-079X / World Scholars http://www.worldscholars.org 


\section{Theoretical Exposition: The Symbiotic Development Paradigm}

For many decades, humankind has engaged in a lingering debate over the real causes of development and underdevelopment around the world. Two schools of knowledge-Modernization and Dependency have featured predominantly in this debate. The Modernization school argues that the west, unlike the Third world such as Africa, is developed because it has socio-political and economic attributes (culture, values $\&$ attitudes) that are progressive and amenable to positive change and development. Thus, the Third world like Africa can experience development if they copy Western values and its artifacts of civilization (Ake, 1979).

On the other hand, Dependency school disagrees with the Modernization thesis, but rather argues that underdevelopment in Africa is a direct consequence of economic exploitation it experienced as a result of Western development which started from slave trade through colonialism to neo-colonialism and which was institutionalized following the disarticulation, monetization and incorporation of African economy into the global economic capitalist system. Hence the only way out of underdevelopment is for Africa to delink and chart a new path to development that is totally independent of the West (Rodney, 1972).

Objectively speaking, both theories have their merits and demerits. We argue that neither of them can single-handedly and adequately address the crisis of development in Africa today. While total delinking is not practicable in this era of globalization, Westernization has been experimented in Africa and it failed. We therefore propose that it is high time the global conversation from North to South, and between Western scholarship and the rest, about the genuine approach to solving the crisis of development, is shifted towards harmonization and unification of the strengths of both theories to evolve a 'symbiotic development paradigm' that is inclusive and beneficial to all peoples and cultures. It is on this type of mutual development framework whose aim will be to uproot global inequalities and poverty, and replace them with prosperity and happiness, that we anchor our analysis.

\section{Millennium Development Goals (MDGs) in Africa: Journey so far}

In 2000, about 189 countries across the various continents of the world endorsed the United Nations Millennium Development Declaration. The Declaration set out eight goals which are to be achieved on or before 2015. These goals include;

- MDG 1: Eradication of extreme poverty and hunger

- MDG 2: Achieving universal primary education
- MDG 3: Promotion of gender equality and women empowerment

- MDG 4: Reduction in child mortality

- MDG 5: Improvement of maternal health

- MDG 6: Combating HIV/AIDS, malaria and other diseases

- MDG 7: Ensuring environmental sustainability

- MDG 8: Developing a global partnership for development (Nigeria: Millennium Development Goals, 2010).

Unfortunately, in Africa, only a few of these goals are likely to be achieved by 2015 . There is no doubt that significant success has been recorded in terms of reduction in child and maternal mortality as well as creation of awareness about HIV/AIDS and malaria, and access to drugs and treatments. However, extreme poverty and hunger, lack of access to basic and quality education, gender inequality and discrimination, environmental degradation and underdevelopment are still prevalent in the continent particularly in the Sub Saharan Africa. For example, in Nigeria, most of the MDGs are not being met and they are unlikely to be achieved unless current efforts are rapidly scaled up. Currently the country is off target in the area of the eradication of extreme poverty and hunger. The percentage of poor people has increased by over 15\% between 1993 and 2004, and this trend is likely to continue for long. Therefore, the goal of reducing the number of poor people to $25 \%$ of the population by 2015 is further off than ever. Malnutrition among children under five has slightly increased, with the level of malnutrition in the Northern part of the country comparable to neighbouring Niger (Federal Republic of NigeriaEuropean Commission Country Strategy, 2008).

Different factors have been blamed for this failure of MDGs in Africa. First is insufficient inflow of international financial aid to African countries to execute MDG programmes. In this regard, Ooms, Stuckler, Basu and McKee, (2010) lament that many of the Millennium Development Goals are not being attained in the world's poorest countries mainly because of insufficient and temporary nature of the financing of these goals as well as poor coordination of aid delivery. This is posing a challenge of achieving MDGs in most needy nations. Hence about 1 billion people are likely to remain in extreme poverty in 2015 and more than 1 out of every 10 school-age children in the world would remain out of school. Thus the target of achieving universal primary education is unlikely to be met and child mortality and maternal deaths would be twice and four times below the target rates, respectively.

They further state that only about half of 120 billion dollars needed yearly from international development institutions and industrialized countries 
to finance the MDGs, is released, and this has made them unattainable in poor countries of Africa. Ethiopia for example, with a population of 80 million people and GDP of 244 dollars per person, spends a total health expenditure of 9 dollars per person every year. This is far below the WHO/MDGs minimum standard of at least 40 dollars per person annually. Even so it should not be ignored that Africa has a very high rate of disease burden. Also, the individual national governments in Africa do not allocate enough funds to the MDGs. For instance, in order to achieve the MDGs in Nigeria by the year 2015, the country needs to spend $\$ 5$ billion to $\$ 7$ billion on MDG programmes every year. Unfortunately, the government is presently allocating about \$1billion per annum to the MDGs, thanks to the debt relief deal from which the 1 billion dollars is raised. But even at that, there is still a deficit of about 4 to 5 billion dollars and it is clear that the public expenditure level by the government is not sufficient enough to meet the MDGs as demonstrated in the Nigeria MDG report 2006 (Centre for Democracy \& Development, 2008).

Another reason why the MDGs are not being realized in Africa is because of what one could call 'misplaced development priorities' orchestrated by international financial institutions and the so-called 'Development Partners'. Most times, the World Bank and IMF give precedence to urban cities and try to fund infrastructural projects there, but pay little attention to rural development. That is why their laudable initiatives such as rural electrification, rural telephony and so on, have all failed. But World Bank/IMF Assisted Projects such as construction of street roads, installation of street lights, provision of potable water etc, can easily be seen in some urban cities. While there is nothing wrong in citing some of these infrastructures in cities, it is also fundamental that the same gesture is replicated in the rural areas because majority of the people, and in some cases, the poor (the lumpen proletariat) live in the rural areas. For example, it is believed that majority of Africans live in the rural area. Therefore, providing the needed social amenities at this level will go a long way in tackling poverty and hunger. It will equally attract industries that can create jobs and reduce rural-to-urban migration. This will certainly contain some of the problems usually experienced in most urban cities in Africa, such as over-crowding, over-stretched infrastructure, the springing up of slums and high unemployment rate.

Moreover, it is believed that the MDGs are yet to be achieved in Africa because of the conditions usually attached to MDG grants from the IMF, World Bank and other development partners which sometimes hinder any concrete effort towards the realization of the MDGs. It is a known fact that more often than not the so-called development partners foist on developing countries reforms and policies that are based on market economy principles irrespective of whether such policies will produce positive results in these countries. Most times, they do not mind cooperating with even corrupt regimes in the Third World inasmuch as such regimes agree to embrace liberal policies like privatization, deregulation and globalization which open up their economies so that the so-called invisible hands of the forces of demand and supply would regulate the prices of goods and services. But this very principle of self-regulating market is not only untenable, but also utopian because government always intervenes and regulates the economy even in advanced capitalist nations (Polanyi, 1957). A good example was the recent use of public funds to the tune of hundreds of billions of dollars as bail-out by the US government during the global economic melt-down to save some of the distressed American private companies like the General Motors (GM), Citi-Bank, to mention but a few, from bankruptcy and possible collapse. More so, government participates in the economy by creating the enabling environment for businesses to thrive, and by also providing social welfare packages like unemployment and health benefits and so on.

It is worthy to note at this juncture that the Western-led-reforms in Africa are at times in conflict with the continent's internal development strategy. This is what Ake (1996:21) called 'competing agendas' and according to him, "nowhere is the conflict more evident than in the rift between the Bretton Woods institutions and African governments over approaches to African Development. The Structural Adjustment Programme (SAP) of 1986 in Nigeria is one of such IMF/World Bank led reform that had catastrophic consequences on the Nigerian economy. Also, the current liberal reforms which tend to influence the choice of development partners in determining who gets what, how and when of funds meant for the MDGs have proved to be abortive. Although Global Financial Institutions claim to have reformed their policy prescriptions particularly for the Third world, they continue to attach pro-cyclical conditions to the financial aid packages they donate to countries in need. These institutions have equally paid insufficient attention to the social implications of such policies (UN, 2011). The prescription of liberal policies by developed nations as the only path to development as well as the requisite qualification for MDG financial assistance is greatly derailing the achievement of the MDGs, at least in Africa. Apart from causing shortage of resources to finance the MDGs in the continent, it has also reinforced the culture of dependency. In this regard, UNDP (2010, p.4) posits that: 
It is clear then that approaching 2015, accelerated progress towards MDG achievements will depend on identifying and unlocking the constraints and bottlenecks in each of these areas. And they are all important. Policies without effective institutions to implement them are meaningless. Policies and institutions without resources are ineffective. The enormous diversity among countries, even within the same region, with respect to their specific conditions, institutions and governance structures implies that accelerated progress on the MDGs will depend on the unique conditions, opportunities and constraints of each country. No single blueprint will do.

In many African countries, the MDG agenda is not captured in the national budgets. And in a few places where it is part of the budget, not enough capital is allocated to it. Most countries in Africa are over dependent on western financial assistance to finance the MDGs. Unfortunately the foreign monetary assistance to Africa in respect to the MDGs has been consistently insufficient.

Also, even in areas where progress has been made in achieving the MDGs in Africa, such success has proven to be unsustainable in a long run because of the dearth of supplementary infrastructure. In Nigeria for instance, some primary health care centres have been built to reduce child and maternal mortality and to boost health care generally, but with neither regular power nor constant water supply provided for their continuous use (Ezehi \& Wasah, 2008:13). This is why the story of the MDGs in Africa could be described as 'one step forward, two steps backward'.

\section{The UN Post-2015 Global Development Agenda: A Rude Awakening for Africa?}

Progress in the MDGs has been uneven across countries and continents of the world as well as among social groups. While South-East Asian countries like China have achieved significant success in poverty reduction, for instance, in many African states and countries in conflict or those coming out of conflict, progress towards poverty reduction has remained fairly small (UN System Task Team on the Post2015 UN Development Agenda, 2012). For example it has been observed that, Nigeria, nay many sub-Saharan African countries will not meet the Millennium Development Goals by 2015 (Okonjo-Iweala, 2012:21). Faced with this disturbing reality and the fact that it would amount to a monumental development calamity especially in the Third world if MDG agenda is not continued beyond 2015, the UN Secretary General - Ban Ki-Moon, in 2012 created the UN System Task Team on the Post2015 Global Development Agenda, and appointed a
27 Member High-Level Panel, with Prime Minister David Cameroon of Britain, President Yudoyono of Indonesia and President Sirleaf Johnson of Liberia as co-chairs with a mandate to design a virile and workable post-MDG development strategy that will be universally acceptable, and which will free the world from extreme want, poverty and hunger, diseases, environmental degradation and wars, and at the same time reposition the world on the path of greater economic prosperity, political stability and peace (UN, 2012).

Be that as it may, it seems Africa will still be mired in poverty and hunger for a long time despite its enormous resources. Given the various factors that have been already discussed in this paper, this is not surprising. What is worrisome however, is that African political leaders are doing little or nothing to address this appalling situation. The leaders appear to be so perpetually overwhelmed by the struggle for political power and their reinforcement that national development and everything else including the MDGs are marginalized. By failing to be at the forefront in determining the contents of the post-2015 Global Development Agenda, Africa is once again taking the back seat in an issue that affects it most. The implication of this is that the continent risks being foisted with a development paradigm that is retrogressive and which promotes the politicoeconomic whims and caprices of the donor nations and their institutions of global hegemony. Vandemoortele (2012:16) captures this vividly when he states that the discourse about the post-MDG agenda has already commenced in developed nations "through their thinktanks, non-governmental organization and donoragencies", but in the "absence of similar debates in developing countries involving grass-root organizations and the voice of the people themselves", there is the tendency for the emergence of a "donor-centric view of the post-2015 agenda and an exceedingly technocratic approach to its formulation". The danger of this scenario is the likelihood of adopting "aid-centric and academic view" of the post-MDG framework by the United Nations. Of course, this will produce adverse effects similar to the Structural Adjustment Programme (SAP) which failed woefully in Africa and further deepened the continent's development crisis.

Again, with the emergence of new threats to global development such as climate change, terrorism and exponential unemployment which were not covered in the MDGs, the future of Africa's development becomes even more disturbing. Global warming is causing drought and flash flooding across the world with gravest impact (death and food insecurity) being felt in Africa even though the continent is the least contributor to green house emissions. It is a worrisome tragedy that Africa has no technology to export to the world. It is 
even more pathetic that the only thing which Africa exports to the world - raw materials from its lush natural vegetations including its flora and fauna are fast being eroded by the changing climate.

Terrorism, which was neither invented by an African nor started from Africa, is now the most potential threat to national security, corporate existence, investments and development of many African states. Unemployment in the continent is rising dramatically such that African labour market remains the largest reservoir of unemployed youth the greatest recipe for crimes and revolution. Suffice it to say that some of these youth do resort to violence and social vices just to make ends meet. All these issues are not captured in the MDGs. Hence some are beginning to question the comprehensiveness and efficacy of the MDGs as a development strategy since the global development needs well exceed these goals, and the process through which they are pursued may equally lead to the creation of a 'Fourth World' because only fewer countries are making progress while many others are being left behind (Centre for International Governance Innovation, 2005).

Therefore, African leaders and the UN System Task Team must take into cognizance these emerging threats and ensure that they are factored into the postMDG development agenda. Any global development strategy that will succeed in this century must not shy away from these issues. Terrorism thrives where there is extreme poverty. That was why Osama Bin Laden could not succeed in selling his terrorist ideology in Saudi Arabia because there is high standard of living there. He however succeeded in sowing and nurturing to maturity the same terrorist ideology in Afghanistan where poverty is pervasive and has created a pool of frustrated and aggressive individuals who want to die so as to put an end to their economic sufferings. World leaders should know that the globe has reached a fragile point where any development strategy that allows a few countries to develop at the expense of others will create two situations that are diametrically opposed - prosperity in the North, while the South becomes a breeding ground for wars, terrorism and terrorists, as well as a launching pad for acts of terror around the world.

The Middle-East is already infiltrated by Al Qaeda and has invariably become a safe haven for terrorists. Terrorism is also beginning to make inroads in the horn of Africa like Somalia and other countries to the North and West of the continent such as Algeria, Libya, Mali and Nigeria. In fact, it is very obvious that neither the developed nor the developing world will be safe or can live a happy life in a cosmos where terrorists are craving for Weapons of Mass Destruction (WMD), for people in such a world will live in constant fears. A world free from want, wars and terror will be for the interest of all, whether developed and developing. And the sure way to bring that world into being is through a global development agenda that is broad, inclusive, mutual and beneficial to all cultures and peoples. Global development planners should be aware that any development approach designed to exploit Africa and the Third world in general will certainly hinder world peace and progress as the unfolding international terrorism and insecurity portray.

Also, the funding of the MDGs is mainly predicated on Overseas Development Assistance, ODA, from developed nations. However, the unfolding economic crisis in Europe and America has shown how unsustainable this arrangement could be. The debt crisis, liquidity deficit and rising unemployment in the US and Euro-Zone countries like Greece, Spain, Italy, Portugal and so on, would mean less foreign financing for the MDGs in particular, and less development assistance to the needy nations in general. There is no doubt that the deepening economic crisis in the west has turned some donor-nations into beggar-nations with some of its population living on charity, hence funding the MDGs is the least item in their budgets. This has some implications:

First is that the MDGs, as a result of inadequate funding, will not be achieved in many African countries especially those that depend heavily on foreign aid to fiancé these goals. Even countries that have made significant success but have no safety-nets to lock in the achievements made so far will also experience some great difficulties. Second, the crisis reveals that any global development agenda that is dependent on foreign financial assistance is vulnerable. Such agenda will be unsustainable in the long run and it may even fail. So, the UN System Task Team should take into consideration the volatility of foreign aid as it designs the post-MDG development strategy. Moreover, the unfolding economic realities in Europe and America should also serve as a wake-up call and lesson for African political leaders who, for decades now have failed to take Africa's destiny into their own hands, but rather consigned it to the developed world. But we must note that "every franc given to impoverished Africans, comes back to France or is smuggled into Switzerland by African bureaucrats and politicians" (Le Monde 1990 cited in Igwe 2010). This shows invariably the role corruption plays in also undermining the MDGs in Africa.

Furthermore, there is an urgent need to re-evaluate the MDGs because some of the goals and the way they are being pursued appear to be creating and recreating poverty, hunger and underdevelopment in Africa. Take for instance, MDG 2 talks about achieving universal primary education. But the fundamental question is; can universal primary education eradicate extreme 
poverty and hunger, and engender development? The truth is that while this level of education is very important, basic education alone is certainly not enough, and cannot end poverty. It is only quality and skilled education that can free peoples from poverty and underdevelopment. The advantage of skilled education is that it produces men and women who reason, job-creators rather than job-seekers. It is the lack of this type of education that is responsible for high graduate unemployment in Africa. There are millions of educated people in Africa today who cannot find job and as a result, are poor. What this indicates is that learning to read and write only is not enough to liberate the world particularly Africa from poverty. The current national education curricula in Africa has created a paradox in the continent whereby every year universities churn out more teachers but who do less teaching, more engineers but less engineering and more doctors but deteriorating health care system. That is why it is common in Africa to see a certified mechanical engineer taking his car that has developed a mechanical fault to a roadside mechanic who did not have primary or secondary education let alone any formal education on engineering.

Another goal worthy of re-examination is MDG 8 which aims at achieving global partnership for development. For us in Africa, a genuine global development partnership that is mutually beneficial to all parties has remained elusive. Over the years, what we experienced in the name of "global partnership for development" have been parasitic bilateral and multilateral relations between developed nations and African states. For instance, bilateral education scholarship (though with some advantages) has become a veritable mechanism through which poaching and hemorrhage of skilled human capital from Africa is sustained. Also, VISA lottery for Africans has become a covert instrument for the sustenance of brain drain though with few cases of brain gain and brain circulation, (Okeke, 2008). For decades now, Africa has been a net supplier of not only mineral resources, but also human capital to Europe and America.

Igwe (2010, p.12) reinforces Okeke's (2008) position when he laments that: Brain drain which began especially in the '90s has continued unabatedly. As at the present an average of 30,000 highly skilled Africans leave the continent each year for the United States and Europe... and according to Archbishop Ndungane...in the United States alone, African immigrants are the highest educated class of all immigrants to that country where there are over 640,000 African professionals over 360,000 of them hold PhDs. 120,000 of them from Nigeria, Ghana, Sudan and Uganda are medical doctors. The rest are professionals in various fields.
If this is what global partnership for development is all about, then it could be said without any fear of equivocation that such partnership is anti-Africa's development. Also, the extant trade relations which have condemned Africa to a perpetual producer and exporter of raw materials under the so-called principle of 'comparative cost advantage' while the developed world continues to enjoy monopoly of producing finished goods particularly technology are exploitative and very unfair. The UN System Task Team should know that if Africa is to be liberated from poverty, its trade relations with the rest of the world must be overhauled and built on symbiotic partnership.

Apart from the need to reassess some of the MDGs, it is also very necessary to reconsider the methods through which these goals are being pursued. The failure of MDGs in Africa and across the globe may not have been a consequence of lack of resources. Perhaps there are enough resources to meet some of the MDGs, but they are not being met because of the way and manner the available resources are being deployed. For example, one of the MDGs is to eradicate extreme poverty and hunger on or before 2015. Today, about 1 billion people are still suffering from starvation and malnutrition which shows that this goal is not being achieved. But is it that there is not enough food to go round? Of course, the answer is no. According to the UK Institute of Mechanical Engineers Report (2013), 4 billion tonnes of food are produced per annum globally out of which 2 billion tonnes are thrown away either due to dearth of storage and processing facilities as in the case of Africa, or thrown into the dustbin by people who have more than they need as in the case of Europe and America.

The report goes further to say that "half of the world total food production is thrown away as waste". That is to say that there is more than enough food to feed the entire world, but extreme hunger has continued unabated due to the lack of proper understanding, co-operation and coordination between the countries that are producing more than enough and those that are producing little. That is why obesity is a common epidemic in the developed nations, while malnutrition and kwashiorkor are pervasive in Africa. Meanwhile, investments in food storage and processing technology, mechanized farming, improved seedlings, irrigation and other modern agricultural techniques will surely liberate Africa from the scourge of hunger. Imagine if the entire Sahara Desert is irrigated, fertilized and converted into a farm settlement. That alone can feed not just the present generation, but also generations unborn. That can transform Africa into a food basket of the world. It is this type of worthy and laudable project that should be factored into the post-2015 global development 
agenda if the comity of nations is truly serious about breaking the jinx of global poverty and hunger.

\section{Implications and Conclusion}

Over a decade of preoccupation with the millennium Development Goals (MDGs) has not yielded the desired results in Africa. Illiteracy, Poverty and hunger, malaria, HIV/AIDS, unemployment and insecurity are still pervasive. Factors like over reliance on foreign funding and stringent conditions that accompany such funding; unjust global development partnership; inadequate educational policy; lack of political will and corruption among African leaders and their indifferent attitude towards development and so on, were found to be individually and collectively responsible for the failure of the MDGs in Africa. Worst still, African Political leadership is playing passive role in shaping the contents of the envisaged post-2015 global development agenda. The likely danger will be the emergence of a post-MDG Agenda that is pro-West and donor nations, and this will not be augur well for Africa's quest for sustainable development.

The implication of this paper is that it has broadened and enlivened the current global debate about what should be the character and contents of the post-2015 Global Development Agenda. It also provided direction for African leaders, majority of whom appear to be indifferent to this global debate.

However, the paper concludes that development will again elude Africa in post-2015 era if its political leaders fail to participate actively in this global debate, and to campaign for a post-MDG framework that is broad, inclusive and beneficial to all peoples and cultures, and which incorporates the new emerging threats (climate change, exponential unemployment and terrorism) to Africa's development.

\section{References}

Ake, C. (1996). Democracy and development in Africa. Ibadan: Spectrum Books Limited.
Ake, C. (1979). Social science as imperialism: The theory of political development. Ibadan: Ibadan University Press.

Centre for Democracy and Development-CDD (2008). Vision 20:2020 and Nigeria's poverty eradication strategy: Reenergizing the policy agenda. A memorandum to the federal government by civil society organizations for the dialogue on Nigeria's current development.

Centre for International Governance Innovation - CIGI (2005). The UN: Adapting to the $21^{\text {st }}$ Century. Conference Report.

Ezehi, M. \& Wasah, C. (2008). Learning lessons: Monitoring and evaluating Nigeria's MDG expenditures. Centre for Democracy and Development (CDD) and Community Action for Popular Participation (CAPP).

Federal Republic of Nigeria-European Commission Country Strategy (2008). Country strategy paper and national indicative programme for the period 2008-2013.

Igwe, S. C. (2010). How Africa underdeveloped Africa. Port Harcourt: Professional Printers \& Publishers.

Nigeria Millennium Development Goals (2010). Countdown strategy 2010-2015: Achieving the Millennium Development Goals (MDGs). Retrieved from: http://www.mdgs.gov.ng

Okeke, G. S. M. (2008). The uprooted emigrant": The impact of brain drain, brain gain and brain circulation on Africa's development. In Falola, T. \& Afolabi, N. (2008) (Eds.) Trans-Atlantic Migration: The Paradoxes of Exile. New York and London: Routledge, 119-139

Okonjo-Iweala, N. (2012). Reforming the Unreformable: Lessons from Nigeria. Cambridge London: The MIT Press.

Ooms, G., Stuckler, D., Basu, S. \& McKee, M. (2010). Financing the millennium development goals for health and beyond: sustaining the big push. Journal for Globalization and Health, 6 (17).

Polanyi, K. (1957). The great transformation. Boston: Boston Press.

Rodney, W. (1972). How Europe underdeveloped Africa. London: Bogle-L'Overtures Publications

UK Institute of Mechanical Engineers Report (2013). Global food waste. BBC World News, $10^{\text {th }}$ January.

UN (2011). The global social crisis: Report on the world social situation. New York: UN Department of Economic and Social Affairs.

UN (2012). Millennium development goals beyond 2015. Sustainable Development Solution Network.

UN System Task Team on the Post2015 UN Development Agenda (2012). Review of the contributions of the MDG Agenda to Foster Development: Lessons for the Post-2015 UN Development Agenda - Discussion Note.

UNDP (2010). Beyond the midpoint: Achieving the millennium development goals. New York: Suazion Inc. and Consolidated Graphics.

Vandemoortele, J. (2012). Advancing the global development agenda post-2015: Some thoughts, ideas and practical suggestions. In UN System Task Team on the Post-2015 UN Development Agenda. 